\title{
Efficacy of Interferon Gamma in the Prevention of SARS-CoV-2 Infection (COVID-19): Results of a Prospective Controlled Trial
}

\author{
Alexander L. Myasnikov, PhD, MD; Svetlana A. Berns, PhD, ScD*; \\ Konstantin V. Zverev, PhD; Olga A. Lartseva; Pavel A. Talyzin \\ GBIH "State Clinical Hospital named after M.E. Zhadkevich DHM" \\ Moscow, the Russian Federation
}

\begin{abstract}
Background: To date, there is no evidence supporting the effectiveness of the use of any drugs for the prevention of COVID-19. However, we have a number of promising drugs at our disposal, which may be potential candidates in COVID-19 prevention. The main aim of this study was to assess the prevalence of COVID-19 among healthy volunteers using nasal INF- $\gamma$ as a preventive measure.

Methods and Results: In this observational prospective study, we used INF- $\gamma$ in a dosage form for intranasal administration to identify a prophylactic effect in volunteers at high risk of getting COVID-19 - medical workers and personnel working in the "red zone." Prophylactic efficacy was evaluated by the incidence of COVID-19 among volunteers when using the study drug (the study group) in comparison with the control group. The mean score on the WHO clinical improvement scale in the two groups was also analyzed. For each participant in the study, initial demographic and epidemiological data were collected: age, gender, the average frequency of acute respiratory viral infection (per year), as well as information on professional activities (work schedule and the number of patients with whom the participant contacts every day). Findings showed that most participants previously had about $45 \%-48 \%$ cases of acute respiratory diseases per year. As a result, we saw good tolerance to COVID-19: $98 \%$ and $86 \%$ of subjects of both groups did not get sick during the period of observation, although the first group showed statistically significant $(P=0.0019)$ better results in disease prevalence. In addition, the comparative analysis demonstrated 0.02 and 0.14 scores of the WHO clinical improvement scale in the study group and control group, respectively $(P=0.0255)$. None of the subjects had adverse events.

Conclusion: This study concluded that there is a potential positive preventive effect of nasal INF- $\gamma$ against ARVI including COVID-19 in healthy volunteers. INF- $\gamma$ use was safe and well tolerated. (International Journal of Biomedicine. 2020;10(3):182-188.)
\end{abstract}

Key Words: interferon gamma $\bullet$ SARS-CoV-2 $\bullet$ COVID-19 $\bullet$ intranasal administration $\bullet$ prevention

\section{Abbreviations}

ACE-2, angiotensin-converting enzyme 2; COVID-19, coronavirus disease 2019; CTCAE, Common Terminology Criteria for Adverse Events; CVD, cardiovascular diseases; DM, diabetes mellitus; GID, gastrointestinal diseases; KLD, kidney and liver diseases; MERS-CoV, Middle East respiratory syndrome; PCR, polymerase chain reaction; SARS, severe acute respiratory syndrome; ARVI, acute respiratory viral infection; ARD, acute respiratory diseases; IFN, interferon

\section{Introduction}

COVID-19, a novel coronavirus infection, was detected in the human population at the end of 2019. The initial outbreak in Wuhan (Hubei Province, China) was represented by a severe

*Corresponding author: Prof. Svetlana A. Berns. Consultant of therapeutic departments of GBIH "State Clinical Hospital named after M.E. Zhadkevich DHM”. Moscow, Russia. Email: svberns@, yandex.ru form of the disease in every fifth case. Severe COVID-19 is associated with a high tropism of the SARS-CoV-2 virus to the lung tissue, which determines its similarity to the pathogenesis of severe acute respiratory syndrome (SARS) registered in 2003. The severity of the disease is associated with age and the presence of concomitant pathologies. ${ }^{(1)}$ The main clinical manifestations of COVID-19 include fever, cough, shortness of breath, and myalgia in most cases. Chest CT can detect the unilateral or bilateral patchy shadows or ground-glass opacities in the lungs. Reports of histological examination of the lungs 
of patients indicate bilateral diffuse alveolar and bronchial damage, pulmonary edema, and hyaline membrane formation, indicative of acute respiratory distress syndrome, accumulation of neutrophils, macrophages, and lymphocytes, ${ }^{(2,3)}$ as well as characteristic syncytial cells in the alveolar lumen. ${ }^{(1,4,5)}$ In addition to acute respiratory symptoms, weight loss can be observed. ${ }^{(6,7)}$

SARS-CoV-2 virus persists in the pharynx, throat, and lungs during the first week of infection and is well defined in a swab from the throat during this time period. A notable difference between SARS-CoV, SARS-CoV-2, and MERS$\mathrm{CoV}$ is the kinetics of virus shedding. Whereas SARS-CoV and MERS-CoV have tropism for lower airways, with less virus present in the upper respiratory tract, this tropism is different in SARS-CoV-2. ${ }^{(8-10)}$ Wolfel et al. ${ }^{(1)}$ reported a detailed virological analysis of nine cases of COVID-19 that provides proof of active virus replication in tissues of the upper respiratory tract. Pharyngeal virus shedding was very high during the first week of symptoms. Later in the disease, COVID-19 resembles SARS in terms of replication in the lower respiratory tract with a prolonged viral load in sputum. Both SARS-CoV-2 and SARS-CoV enter host cells via the angiotensin-converting enzyme 2 (ACE2) receptor, which is expressed in various human organs. The concurrent use of ACE2 as a receptor by SARS-CoV and SARS-CoV-2 corresponds to a highly similar excretion kinetic in sputum, with active replication in the lung. ${ }^{(11)}$ In a study by Wolfel et al., (11) the shedding of viral RNA from sputum outlasted the end of symptoms. Seroconversion occurred after 7 days in $50 \%$ of patients (and by day 14 in all patients), but was not followed by a rapid decline in viral load. The conjunctival epithelium and conducting airways appear to be potential portals of infection for SARS-CoV-2. Both SARS-CoV and SARS-CoV-2 replicated similarly in the alveolar epithelium; SARS-CoV-2 replicated more extensively in the bronchus than SARS-CoV. These findings provide important insights into the transmissibility and pathogenesis of SARS-CoV-2 infection and differences with other respiratory pathogens. ${ }^{(12,13)}$ The confirmation of active virus replication in the upper respiratory tract has implications for the containment of COVID-19. ${ }^{(11)}$ In SARS-CoV-2 infection, the virus was detected in type I and II pneumocytes in foci of diffuse alveolar damage and in ciliated epithelial cells of nasal, bronchial, and bronchiolar mucosae. In SARS-CoV and SARS-CoV-2 infections, lung lesions are typically more severe, whereas they are milder in MERS$\mathrm{CoV}$ infection, where the virus is detected mainly in type II pneumocytes. ${ }^{(1)}$

Active replication of the virus in the lower respiratory tract is associated with the development of complications and lung damage. ${ }^{(1)}$ Older adults are susceptible to severe coronavirus disease 2019 (COVID-19) outcomes as a consequence of their age and, in some cases, underlying health conditions. ${ }^{(14)}$

It should be noted that the acquired immunity against coronavirus infections is not stable and does not protect against re-infection.

To date, there is no evidence supporting the effectiveness of the use of any drugs for the prevention of COVID-19. However, we have a number of promising drugs at our disposal, which may be potential candidates in COVID-19 prevention. ${ }^{(15-17)}$ Interferons are one of these potential candidates.

Interferons are the most important components of the innate antiviral immune response. ${ }^{(18-21)}$ Type I IFNs (IFN- $\alpha$ and IFN- $\beta$ ) have a unique ability to directly induce an antiviral response through the up-regulation of molecules that can antagonize virus replication. ${ }^{(22)}$ Type I IFNs are also essential for activating natural killer (NK) cells, ${ }^{(23)}$ which produce IFN- $\gamma$ (type II IFN). (23-26) IFN $\gamma$ is also released in large amounts by macrophages, activated CD8 T cells, and Th1 CD4 T cells. IFN- $\gamma$ is a key link between the innate immune response and activation of the adaptive immune response. ${ }^{(24)}$ IFN $\gamma$ is a potent chemoattractant promoting the recruitment of neutrophils, and $\mathrm{T}$ cells through paracrine signaling. IFN $\gamma$ up-regulates antigen presentation on epithelial cells. ${ }^{(27)}$ The impact of IFN- $\gamma$ on antigen-presenting cells is to enhance stimulation of the adaptive antiviral response to both clear the infection and generate memory as a safeguard for future infections. ${ }^{(28,29)}$ IFN- $\gamma$ has complementary effects on inducing an antiviral macrophage function. ${ }^{(24,30)}$

Several different IFNs are currently FDA approved to treat a variety of infections. Type I IFNs have been used clinically as therapeutics against both hepatitis $\mathrm{B}$ and $\mathrm{C}$ infections. ${ }^{(31,32)}$ Due to its profound immune-modulatory abilities, IFN- $\gamma$ has been used as a prophylactic measure to cure several infections. ${ }^{(33)}$ IFN- $\gamma$ actions against influenza virus, herpes simplex virus, HPV, and HIV have been described in many studies. ${ }^{(34-37)}$ Rhein et al. demonstrated the ability of IFN $\gamma$ to protect animals both prophylactically and therapeutically against Ebola virus (EBOV) infection. ${ }^{(38)}$

Ingaron $\AA$ (IFN- $\gamma$ human recombinant, manufactured by SPP Pharmaclon Ltd., Russia) is presented in two dosage forms: lyophilisate for the preparation of a solution for intranasal administration, as well as intramuscular or subcutaneous administration. Efficacy and safety in the prevention and treatment of viral infections, including coronavirus nature, flu, and pneumonia, have been shown in randomized controlled and placebo-controlled clinical trials. ${ }^{(39-41)} \mathrm{A}$ drug for intranasal administration based on recombinant IFN- $\gamma$ was studied to evaluate the effectiveness of prophylactic administration during the period of an epidemic increase in the incidence of influenza and SARS. According to the results of a placebocontrolled randomized study of using recombinant IFN- $\gamma$ in the complex therapy of patients with influenza A, the disease incidence during the period of prophylaxis and within a one-month follow-up period after 2 ten-day cycles of drug administration decreased by more than 2 times. Among those who nevertheless fell ill, a complicated course of infection was observed 2 times less likely. ${ }^{(41)}$ The results of the clinical study of the efficacy and safety of IFN- $\gamma$ (Ingaron100,000 IU, a lyophilisate for the preparation of a solution for intranasal administration) in treatment of influenza-like infections showed high antiviral and detoxification efficacy. ${ }^{(42)}$

Ingaron was included in the training manual "New coronavirus infection COVID-19: etiology, epidemiology, clinic, diagnosis, treatment and prevention" ${ }^{(15)}$ and is recommended by the Expert Council for Science of the Moscow Department of Health as a preventive measure against COVID-19. ${ }^{(43)}$ 
Intranasal drug administration has a long tradition. The nasal mucosa can be used for non-invasive systemic administration of drugs. Due to the presence of the so-called mucosa-associated lymphoid tissue, ${ }^{(44)}$ intranasal IFN- $\gamma$ administration induces mucosal (protection at the site of infection) and systemic immunity. An important aspect is that intranasal administration is easy to do for self-administration. Intranasal drug delivery has a favorable safety profile.

Susceptibility to SARS-CoV-2 $2^{(15,43,45)}$ is high in all populations. Nonetheless, attending physicians and medical personnel assisting and caring for patients infected with SARS$\mathrm{CoV}-2$ are certainly at particular risk. The main aim of this study was to assess the effectiveness and safety of prophylactic therapy with INF- $\gamma($ Ingaron $\AA$, lyophilizate for the preparation of 100,000 IU solution for intranasal use, manufactured by SPP Pharmaclon Ltd., Russia) among volunteers - medical workers and personnel working in the "red zone" of the State Clinical Hospital named after M.E. Zhadkevich (Moscow, Russia).

\section{Materials and Methods}

During the observational program, the efficacy and safety of intranasal INF- $\gamma$ for the prevention of viral infection caused by COVID-19 among medical personnel working (about 30 hours a week) in direct contact with infected patients (about 20 people a day) were evaluated.

\section{Study inclusion criteria:}

- A signed informed consent document indicating that the subject has been informed of all pertinent aspects of the study prior to initiation of any subject-mandated procedures

- Male or female aged 18 years and older

- Medical staff and nursing working in the "red zone" in direct contact with infected patients

- No symptoms suggestive of SARS-CoV-2 or any respiratory infection

- $\quad$ Negative PCR result of SARS-CoV-2 nucleic acid test in nasopharyngeal swab

Study non-inclusion criteria:

- The presence of specific IgG and IgM against SARSCoV-2 (ELISA test)

- Exacerbation of concomitant diseases that can affect the results of the study

- Use of drugs that can affect the results of the study

- Contraindications to the use of investigational drug

- $\quad$ Pregnancy or breastfeeding

Primary Outcome Measures:

- The incidence rate of common clinical symptoms of COVID-19 (fever, cough, and shortness of breath) [Time Frame: 27 days]

- The incidence rate of confirmed symptomatic infections of SARS-CoV-2 ((PCR with RealBest RNA SARSCoV-2 (VectorBest, Russia) and/or IgG/IgM antibodies to SARS-CoV-2 (ELISA with Coronavirus Disease 2019 Antibody (IgM/IgG) Combined Test Kit Dixion, Mindray, China)) [Time Frame: 27 days]

Secondary Outcome Measures:
- Severity of disease and average score on the WHO clinical improvement scale [Time Frame: 27 days]

- Less common signs and symptoms of SARS-CoV-2 (COVID-19) infection (headache, muscle pain, abdominal pain, sputum production, and sore throat) [Time Frame: 27 days]

To evaluate the frequency and severity of adverse events, laboratory test results, as well as the general tolerability of the drug during prophylactic administration according to the CTCAE 4.03 scale were used.

According to the methodology approved by the observational program, a participant had to use or not the investigational drug (depending on his/her own will) within 27 days of the preventive course (10 days of use +7 days of break +10 days of use). The control group did not receive investigational preventive therapy.

Participants of the study were employees who voluntarily expressed a desire to participate in the study, signed an informed consent form, and completed the worksheet. The first 50 volunteers who expressed such a desire to use IFN- $\gamma$ for prophylactic purposes were included in the study group. The first 50 volunteers who expressed a desire to participate in the study, but without taking the investigational drug, were included in the control group. After the total inclusion of 100 subjects, enrollment in the study was closed. However, for ethical reasons, other volunteers who expressed a desire to take IFN- $\gamma$ for prophylactic purposes received this opportunity without collecting personal data.

All subjects enrolled in the study underwent the following examinations: assessment of risk factors, demographic and anamnesis data collection, and nasopharyngeal smear. Nasopharyngeal swabs were obtained before and after the completion of prophylactic observation.

Data collection was performed using special worksheet of the observational study containing questions concerning date of birth, contraindications to investigational drug use, working functions, number of patients with COVID-19 used to deal with per day, average incidence of ARD per year, side effects and prevention efficacy, etc. The worksheet was divided into 2 parts: Part 1 was filled out by the participant, Part 2 - by the investigator. To reduce the risk of contamination of the document and the transmission of the infectious agent through paper versions, it was recommended that the worksheet was sent by the subject to the investigator with the electronic means with a seal and signature by the researcher in the "green zone".

The study was conducted in accordance with ethical principles of the WMA Declaration of Helsinki (1964, ed. 2013) and approved by the Ethics Committee of the State Clinical Hospital named after M.E. Zhadkevich.

Statistical analysis was performed using statistical software package SPSS v.17.0 (SPSS Inc, Chicago, IL). Baseline characteristics were summarized as frequencies and percentages for categorical variables and as mean \pm standard deviation (SD) for continuous variables. For data with normal distribution, intergroup comparisons were performed using Student's t-test. Group comparisons with respect to categorical variables were performed using $\chi 2$ test or, alternatively, Fisher's exact test. A probability value of $P<0.05$ was considered statistically significant. 


\section{Results and Discussion}

We examined 100 subjects ( $81 \%$ women and $19 \%$ men aged between 21 and 62 years, mean age of $40.4 \pm 9.3$ years) with no symptoms of acute respiratory infection verified by standardized validated tests of PCR detecting SARS-CoV-2 viral antigens in a nasopharyngeal swab. The presence of specific IgG and IgM against SARS-CoV-2 (ELISA test) in the blood was estimated as non-inclusion criteria at the screening visit.

All subjects were divided into two groups (1:1): the study group (SG) included 50 subjects who took INF- $\gamma$ for prophylactic purposes, the control group (CG) included 50 subjects who did not use the investigational drug. The characteristics of the compared groups are presented in Table 1 . The analysis did not reveal statistically significant differences between groups $(\mathrm{P}>0.05)$ in critical parameters.

\section{Table 1.}

The characteristics of the compared groups

\begin{tabular}{|l|c|c|c|}
\hline \multicolumn{1}{|c|}{ Variable } & Study group & Control group & $P$-value \\
\hline Age, years $(\mathrm{M} \pm \mathrm{SD})$ & $40.9 \pm 9.7$ & $39.9 \pm 8.9$ & 0.5924 \\
\hline Male, $\%$ & 20 & 18 & 0.7989 \\
\hline Female, \% & 80 & 82 & 0.7987 \\
\hline $\begin{array}{l}\text { Average incidence of } \\
\text { ARD, number per year } \\
(\mathrm{M} \pm \mathrm{SD})\end{array}$ & $3.5 \pm 1.7$ & $3.0 \pm 1.7$ & 0.1446 \\
\hline Smoking, \% & 62 & 58 & 0.6827 \\
\hline CVD, \% & 18 & 18 & 1.000 \\
\hline DM, \% & 18 & 8 & 0.1371 \\
\hline GID, \% & 46 & 44 & 0.8414 \\
\hline KLD, \% & 0 & 0 & 1.000 \\
\hline Other diseases, \% & 0 & 0 & 1.000 \\
\hline
\end{tabular}

The study involved nurses (52\%), doctors (30\%), and junior staff $(18 \%)$. Nursing staff performed injections and infusions. Junior staff was involved in overcrowding of beds, sanitary and hygiene items, and caring activities. Doctors examined patients and appointed therapy. In both groups, all participants used respirators, gloves, glasses, and suits as a non-specific preventive measure. In CG, 4(8\%) participants used the drugs Arbidol ( 2 people) and Anaferon ( 2 people) for disease prevention. No statistically significant differences between the groups for this parameter were revealed.

All participants worked in the "red zone" of the State Clinical Hospital named after M.E. Zhadkevich during the period from $04 / 2020$ to $06 / 2020$. None of the study participants dropped out of the study ahead of schedule.

According to the primary outcome measures of the disease prevalence, significant differences between the two groups were found with lower incidence in $\mathrm{SG}(P=0.0019)$. The level of laboratory confirmation of COVID-19 clinical cases in $\mathrm{SG}$ was also lower than in CG, although no significance was found. The maximum score on the WHO clinical improvement scale in both groups did not exceed 1. Moreover, the difference in average values revealed significant differences between groups in this parameter in favor of SG (Table 2).

Table 2.

The parameters of the preventive efficiency in the compared groups

\begin{tabular}{|l|c|c|c|}
\hline \multicolumn{1}{|c|}{ Variable } & $\begin{array}{c}\text { Study } \\
\text { group }\end{array}$ & $\begin{array}{c}\text { Control } \\
\text { group }\end{array}$ & $\begin{array}{c}P \text {-value } \\
\text { (2-tailed test) }\end{array}$ \\
\hline Incidence of disease, \% & 2 & 14 & 0.0019 \\
\hline $\begin{array}{l}\text { Laboratory confirmed } \\
\text { incidence of disease, \%^ }\end{array}$ & 2 & 6 & 0.2687 \\
\hline $\begin{array}{l}\text { WHO Clinical } \\
\text { improvement scale score } \\
(\mathrm{M} \pm \mathrm{SD})\end{array}$ & $0.02 \pm 0.140$ & $0.14 \pm 0.347$ & 0.0255 \\
\hline
\end{tabular}

${ }^{\wedge} P C R$ and/or ELISA positive results in those participants who manifested clinical signs of COVID-19

Complaints about symptoms of intoxication, such as headache, dizziness, weakness, fever, etc., which are characteristic of the course of the underlying disease, were not recorded as adverse events. During the study, not a single adverse event was noted, including a serious one. Thus, the study drug confirmed a good safety profile and good tolerance in the study population.

The incidence of laboratory-confirmed cases of COVID-19 was less than the incidence of clinical symptoms without laboratory confirmation and did not show statistical significance, probably due to insufficient sample size. Limitations of the study included exclusively voluntary participation of research subjects and the recruitment of participants on the basis of one research center, in this regard, the sample size was small. In addition, all medical workers used the maximum possible personal protective equipment.

Taking into account the inclusion criteria (staff working in the "red zone"), the selected population was at risk for the disease COVID-19. The identification of other viruses has not been supposed by the clinical routine. The nucleic acid test is a gold standard of laboratory diagnostics of COVID-19. ${ }^{(46)}$ The sensitivity of the test varies from $19 \%$ to $59 \%$, while specificity almost $100 \%$ that is the reason for a high rate of false positive results. ${ }^{(47)}$ In this connection, it was assumed that the presence of key prevailing clinical symptoms indicates primarily COVID-19 due to the epidemiological situation and working conditions of participants. Such an approach based mainly on clinical evidence without PCR testing results has been described concerning the detection of risk groups of patients who are more likely to have COVID-19. ${ }^{(48)}$

It should be noted that all the participants manifested clinical symptoms similar to ARVI caused by SARS-CoV-2: fever (up to $38^{\circ} \mathrm{C}$ ), and dry cough. Fever and cough are the main COVID-19 symptoms detected in 88\%-98\% and 68\%$76 \%$ of cases, respectively, showing a high correlation with the disease incidence. ${ }^{(49,50)}$ The severity of the disease was mild, lasting an average of 4 days in both groups, and none of the subjects required hospitalization.

Technical reasons for false negative results of laboratory tests to confirm COVID-19 include the wrong procedure of 
nasopharyngeal swab sample taking and timing of analysis after sample taking. ${ }^{(51)}$

The quality of a sample correlates with the efficiency and accuracy of the test of viral nucleic acid extraction. However, the procedure of reaching the nasopharynx is not easy because of the high variability of the intranasal anatomy and requires training, skills, and practical experience that are limited due to emergency. A patient usually feels discomfort during the procedure that may also result in wrong diagnostic sampling performance. ${ }^{(52)}$

Once collected, the sample should be examined as soon as possible. The faster the analysis performance, the higher the probability of detecting antigens. RNA of the virus is easily destroyed. ${ }^{(53)}$

In addition, there is a range of factors independent of sampling technique but associated with the defect of the test kits themselves, like lack of specificity of a gene locus, low product stability, etc. ${ }^{(54)}$

Besides, the test in nasopharyngeal swab is less precise than in sputum or other lower respiratory tract secretions. However, sputum analysis was not supposed by the study design, and sputum was registered in none of the disease cases. Generally, only about $28-30 \%$ of patients complain of sputum appearance. Less than half of patients have manifestations of myalgia, fatigue, diarrhea, acute respiratory distress syndrome. ${ }^{(49)}$

Serological testing is not a gold standard of SARSCoV-2 confirmation, although widely used in clinical practice as an additional method to detect COVID-19 cases. Current epidemiological studies show that the incubation period is up to 14 , most often around 5 days. ${ }^{(55)}$ For the right interpretation of test results, medical proof is still required. No relevant clinical studies, only previous experience with viral infections, formed the basis of the test interpretation rules. Typically, antibodies are produced after infection. Detection of antibodies indicates that there is antigen stimulation, including current illness, or previous infection, or antigen exposure, not necessarily an infectious disease. Thus, IgM positive result indicates the possibility of early infection, however, does not exclude a false positive result. Both IgM and IgG negative results besides false negative results might mean a "window period." The rate of false positive or negative results is unknown. No distinction can be made between a present infection, a past infection, or just close contact based on a serological test. ${ }^{(56)}$

Thus, our study showed that the course of INF- $\gamma$ is effective in the prevention of ARVI, including COVID-19 infection (Figure 1) that confirm the data received in other studies evaluated antiviral properties of the drug. ${ }^{(39-41)}$

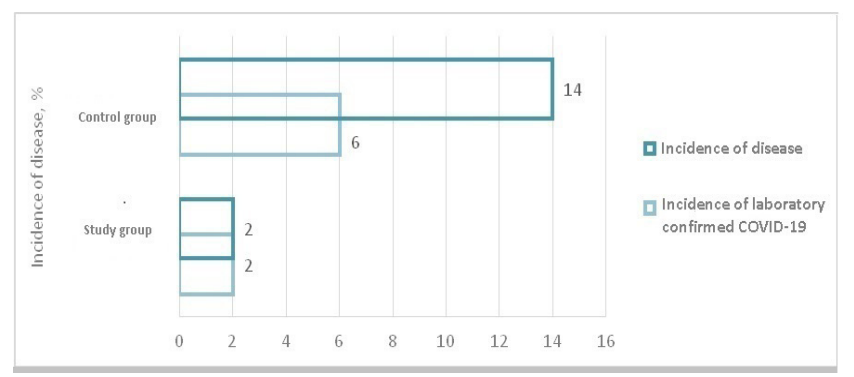

Fig. 1. Preventive efficiency of interferon gamma
INF- $\gamma$ for intranasal use has confirmed high safety and good tolerance. It seems advisable to use intranasal IFN- $\gamma$ administration to reduce the risk of infection of medical workers in an epidemic caused by COVID-19. Further largescale clinical trials are needed to confirm the efficacy and safety of intranasal INF- $\gamma$ in the prevention of COVID-19 in contact individuals.

\section{Acknowledgments}

We thank SPP Pharmaclon Ltd for the investigational drug and its specialists for their technical support within the research program.

\section{Competing Interests} interests.

The authors declare that they have no competing

\section{References}

1. Rockx B, Kuiken T, Herfst S, Bestebroer T, Lamers MM, Munnink BBO, et al. Comparative pathogenesis of COVID-19, MERS, and SARS in a nonhuman primate model. Science. 2020;368(6494):1012-1015. doi: 10.1126/science. abb7314.

2. Shi H, Han X, Jiang N, Cao Y, Alwalid O, Gu J, et al. Radiological findings from 81 patients with COVID-19 pneumonia in Wuhan, China: a descriptive study. Lancet Infect Dis. 2020;20(4):425-434. doi:10.1016/S1473-3099(20)30086-4 3. Ware LB, Matthay MA. The acute respiratory distress syndrome. N Engl J Med. 2000;342(18):1334-1349. doi:10.1056/NEJM200005043421806

4. Xu Z, Shi L, Wang Y, Zhang J, Huang L, Zhang C, et al. Pathological findings of COVID-19 associated with acute respiratory distress syndrome [published correction appears in Lancet Respir Med. 2020 Feb 25]. Lancet Respir Med. 2020;8(4):420-422. doi:10.1016/S2213-2600(20)30076-X

5. Tian $\mathrm{S}, \mathrm{Hu} \mathrm{W}$, Niu L, Liu $\mathrm{H}, \mathrm{Xu} \mathrm{H}$, and Xiao SY. Pulmonary Pathology of Early-Phase 2019 Novel Coronavirus (COVID-19) Pneumonia in Two Patients With Lung Cancer. J Thorac Oncol. 2020;15(5):700-704. doi:10.1016/j. jtho.2020.02.010

6. Bao L, Deng W, Gao H, Xiao C, Liu J, Xue J, et al. Reinfection could not occur in SARS-CoV-2 infected rhesus macaques. bioRxiv. 2020. doi: 10.1101/2020.03.13.990226.

7. Munster VJ, Feldmann F, Williamson BN, Van Doremalen N, Pérez-Pérez L, Schulz J, et al. Respiratory disease and virus shedding in rhesus macaques inoculated with SARS-CoV-2. Preprint. bioRxiv. 2020;2020.03.21.001628. Published 2020 Mar 21. doi:10.1101/2020.03.21.001628

8. Petersen E, Koopmans M, Go U, Hamer DH, Petrosillo $\mathrm{N}$, Castelli F, et al. Comparing SARS-CoV-2 with SARS-CoV and influenza pandemics [published online ahead of print, 2020 Jul 3]. Lancet Infect Dis. 2020;S1473-3099(20)30484-9. doi:10.1016/S1473-3099(20)30484-9

9. Zou L, Ruan F, Huang M, Liang L, Huang H, Hong Z, et al. SARS-CoV-2 Viral Load in Upper Respiratory Specimens of Infected Patients. N Engl J Med. 2020;382(12):1177-1179. doi:10.1056/NEJMc2001737

10. Peiris JSM, Chu CM, Cheng VCC, Chan KS, Hung IFN, Poon LLM, et al. Clinical progression and viral load in a community outbreak of coronavirus-associated SARS pneumonia: a prospective study. Lancet. 2003;361(9371):1767- 
1772. doi:10.1016/s0140-6736(03)13412-5

11. Wölfel R, Corman VM, Guggemos W, Seilmaier M, Zange S, Müller MA, et al. Virological assessment of hospitalized patients with COVID-2019. Nature. 2020;581(7809):465469. doi:10.1038/s41586-020-2196-X

12. Hui KPY, Cheung MC, Perera RAPM, Ng KC, Bui CHT, Ho JCW, et al. Tropism, replication competence, and innate immune responses of the coronavirus SARS-CoV-2 in human respiratory tract and conjunctiva: an analysis in ex-vivo and in-vitro cultures. Lancet Respir Med. 2020;8(7):687-695. doi:10.1016/S2213-2600(20)30193-4

13. Kimball A, Hatfield KM, Arons M, James A, Taylor J, Spicer K, et al. Asymptomatic and Presymptomatic SARS-CoV-2 Infections in Residents of a Long-Term Care Skilled Nursing Facility - King County, Washington, March 2020. MMWR Morb Mortal Wkly Rep. 2020;69(13):377-381. Published 2020 Apr 3. doi:10.15585/mmwr.mm6913e1

14. CDC COVID-19 Response Team. Severe Outcomes Among Patients with Coronavirus Disease 2019 (COVID-19) - United States, February 12-March 16, 2020. MMWR Morb Mortal Wkly Rep. 2020;69(12):343-346. Published 2020 Mar 27. doi:10.15585/mmwr.mm6912e2

15. Nikiforov VV, Suranova TG, Mironov AJu and Zabozlaev FG. [New coronavirus infection (COVID-19): etiology, epidemiology, clinic, diagnosis, treatment and prevention]. Moscow; 2020. [in Russian].

16. Lu H. Drug treatment options for the 2019-new coronavirus (2019-nCoV). Biosci Trends. 2020;14(1):69-71. doi:10.5582/bst.2020.01020

17. Zhang L, Liu Y. Potential interventions for novel coronavirus in China: A systematic review. J Med Virol. 2020;92(5):479-490. doi:10.1002/jmv.25707

18. Costa-Pereira AP, Williams TM, Strobl B, Watling D, Briscoe J, Kerr IM. The antiviral response to gamma interferon. J Virol. 2002;76(18):9060-9068. doi:10.1128/ jvi.76.18.9060-9068.2002

19. Lee AJ, Ashkar AA. The Dual Nature of Type I and Type II Interferons. Front Immunol. 2018;9:2061. Published 2018 Sep 11. doi:10.3389/fimmu.2018.02061

20. Shan L, Fu F, Xue M, Zhu X, Li L, Feng L, et al. Interferon gamma inhibits transmissible gastroenteritis virus infection mediated by an IRF1 signaling pathway. Arch Virol. 2019;164(11):2659-2669. doi:10.1007/s00705-019-04362-2

21. Rhein BA, Powers LS, Rogers K, Anantpadma M, Singh BK, Sakurai Y, et al. Interferon- $\gamma$ Inhibits Ebola Virus Infection. PLoS Pathog. 2015;11(11):e1005263. Published 2015 Nov 12. doi:10.1371/journal.ppat.1005263

22. Meurs E, Chong K, Galabru J, Thomas NS, Kerr IM, Williams BR, et al. Molecular cloning and characterization of the human double-stranded RNA-activated protein kinase induced by interferon. Cell. 1990;62(2):379-390. doi:10.1016/0092-8674(90)90374-n

23. Lee AJ, Chen B, Chew MV, Barra NG, Shenouda MM, Nham $T$, et al. Inflammatory monocytes require type I interferon receptor signaling to activate $\mathrm{NK}$ cells via IL-18 during a mucosal viral infection. J Exp Med. 2017;214(4):1153-1167. doi:10.1084/jem.20160880

24. Karupiah G, Xie QW, Buller RM, Nathan C, Duarte C, MacMicking JD. Inhibition of viral replication by interferon-gamma-induced nitric oxide synthase. Science. 1993;261(5127):1445-1448. doi:10.1126/science.7690156

25. Weizman OE, Adams NM, Schuster IS, Krishna C, Pritykin Y, Lau C, et al. ILC1 Confer Early Host Protection at
Initial Sites of Viral Infection. Cell. 2017;171(4):795-808.e12. doi:10.1016/j.cell.2017.09.052

26. Vivier E, Tomasello E, Baratin M, Walzer T, Ugolini S. Functions of natural killer cells. Nat Immunol. 2008;9(5):503-510. doi:10.1038/ni1582

27. Bhat P, Leggatt G, Waterhouse N, Frazer IH. Interferon- $\gamma$ derived from cytotoxic lymphocytes directly enhances their motility and cytotoxicity. Cell Death Dis. 2017;8(6):e2836. Published 2017 Jun 1. doi:10.1038/cddis.2017.67

28. Goldszmid RS, Caspar P, Rivollier A, White S, Dzutsev A, Hieny $\mathrm{S}$, et al. NK cell-derived interferon-gamma orchestrates cellular dynamics and the differentiation of monocytes into dendritic cells at the site of infection. Immunity. 2012;36(6):1047-1059. doi:10.1016/j.immuni.2012.03.026

29. Martin-Fontecha A, Thomsen LL, Brett S, Gerard C, Lipp M, Lanzavecchia A, et al. Induced recruitment of NK cells to lymph nodes provides IFN-gamma for $\mathrm{T}(\mathrm{H}) 1$ priming. Nat Immunol. 2004;5(12):1260-1265. doi:10.1038/ni1138

30. Kang K, Park SH, Chen J, Qiao Y, Giannopoulou E, Berg $\mathrm{K}$, et al. Interferon-gamma represses $\mathrm{M} 2$ gene expression in human macrophages by disassembling enhancers bound by the transcription factor MAF. Immunity. 2017;47(2):235-250. e4. doi:10.1016/j.immuni.2017.07.017

31. Cooksley WG. Treatment of hepatitis B with interferon and combination therapy. Clin Liver Dis. 2004;8(2):353-370. doi:10.1016/j.cld.2004.02.004

32. Shepherd J, Waugh N, Hewitson P. Combination therapy (interferon alfa and ribavirin) in the treatment of chronic hepatitis C: a rapid and systematic review. Health Technol Assess. 2000;4(33):1-67.

33. Kak G, Raza M, Tiwari BK. Interferon-gamma (IFN- $\gamma$ ): Exploring its implications in infectious diseases. Biomol Concepts. 2018;9(1):64-79. Published 2018 May 30. doi:10.1515/bmc-2018-0007

34. Don ES, Emelyanova AG, Yakovleva NN, Petrova NV, Nikiforova MV, Gorbunov EA, et al. Dose-dependent antiviral activity of released-active form of antibodies to interferon-gamma against influenza A/California/07/09(H1N1) in murine model. J Med Virol. 2017;89(5):759-766. doi: 10.1002/jmv.24717.

35. Berri F, Haffar G, Lê VB, Sadewasser A, Paki K, Lina $\mathrm{B}$, et al. Annexin $\mathrm{V}$ incorporated into influenza virus particles inhibits gamma interferon signaling and promotes viral replication. J Virol. 2014;88(19):11215-28. doi: 10.1128/ JVI.01405-14.

36. Verhoeven D, Perry S, Pryharski K. Control of influenza infection is impaired by diminished interferon- $\gamma$ secretion by CD4 T cells in the lungs of toddler mice. J Leukoc Biol. 2016;100(1):203-12. doi: 10.1189/jlb.4A1014-497RR.

37. Theeten H, Mathei C, Peeters K, Ogunjimi B, Goossens H, Ieven M, Van Damme P, Cools N. Cellular Interferon Gamma and Granzyme B Responses to Cytomegalovirus-pp65 and Influenza N1 Are Positively Associated in Elderly. Viral Immunol. 2016;29(3):169-75. doi: 10.1089/vim.2015.0071.

38. Rhein BA, Powers LS, Rogers K, Anantpadma M, Singh BK, Sakurai Y, et al. Interferon- $\gamma$ Inhibits Ebola Virus Infection. PLoS Pathog. 2015;11(11):e1005263. Published 2015 Nov 12. doi:10.1371/journal.ppat.1005263

39. Sologub TV, Golobokov GS, Cvetkov VV and Tokin II. [Interferon-gamma in the treatment of influenza and other respiratory viral infections]. Medicinskij Sovet. 2015;7. [Article in Russian].

40. Nikiforov VV, Sologub TV, Tokin II, Cvetkov VV, Erofeeva MK and Zarubaev VV. [Possibility of using interferon-y for 
influenza infection]. Jepidemiologija i Infekcionnye Bolezni. 2015;20(3). [Article in Russian].

41. Midikari AS, Agafonov VN, Suzdal'cev AA and Cvetkov VV. [Efficiency and expediency of using recombinant interferon-gamma in the complex therapy of patients with influenza A (H1N1) PDM09]. Jepidemiologija i Infekcionnye Bolezni. 2017;22(2). [Article in Russian].

42. Tokin II, Nikiforov VV, Shabalkin PI, Pimanchev PV, Isakova JA and Tsvetkov VV. Randomized Controlled ParallelDesign Clinical Study of the Efficacy and Safety of Intranasal Interferon gamma in Treatment of Influenza-Like Infections. International Journal of Biomedicine. 2018;8(4):327-332. doi: 10.21103/article8(4)_oa12.

43. Smetanina CV, Nikiforov VV, Kolobuhina LV. [New coronavirus infection (COVID-19): etiology, epidemiology, clinic, diagnosis, treatment and prevention]. Moscow: Moscow City Government, Moscow City Health Department; 2020. [in Russian].

44. Elmore SA. Enhanced histopathology of mucosaassociated lymphoid tissue. Toxicol Pathol. 2006;34(5):687696. doi:10.1080/01926230600939989

45. Chen N, Zhou M, Dong X, Qu J, Gong F, Han Y, et al. Epidemiological and clinical characteristics of 99 cases of 2019 novel coronavirus pneumonia in Wuhan, China: a descriptive study. Lancet. 2020;395(10223):507-513. doi:10.1016/S01406736(20)30211-7

46. Carter LJ, Garner LV, Smoot JW, Li Y, Zhou Q, Saveson CJ, et al. Assay Techniques and Test Development for COVID-19 Diagnosis. ACS Cent Sci. 2020;6(5):591-605. doi:10.1021/acscentsci.0c00501

47. Kucirka LM, Lauer SA, Laeyendecker O, Boon D and Lessler J. Variation in False-Negative Rate of Reverse Transcriptase Polymerase Chain Reaction-Based SARSCoV-2 Tests by Time Since Exposure. Ann Intern Med. 2020;173(4):262-267. doi:10.7326/M20-1495

48. Sun Y, Koh V, Marimuthu K, Ng OT, Young B, Vasoo S, et al. Epidemiological and Clinical Predictors of COVID-19. Clin Infect Dis. 2020;71(15):786-792. doi:10.1093/cid/ciaa322
49. Huang C, Wang Y, Li X, Ren L, Zhao J, Hu Y, et al. Clinical features of patients infected with 2019 novel coronavirus in Wuhan, China [published correction appears in Lancet. 2020 Jan 30]. Lancet. 2020;395(10223):497-506. doi:10.1016/ S0140-6736(20)30183-5

50. Guan WJ, Ni ZY, Hu Y, Liang WH, Ou CQ, He JX, et al. Clinical Characteristics of Coronavirus Disease 2019 in China. N Engl J Med. 2020;382(18):1708-1720. doi:10.1056/ NEJMoa2002032

51. Tagliabue M, Pietrobon G, Ugolini S, Chu F, Ansarin M. Nasopharyngeal swabs during SARS-CoV-2 pandemic: a role for the otolaryngologist. Eur Arch Otorhinolaryngol. 2020;277(7):2155-2157. doi:10.1007/s00405-020-06027-2

52. Marty FM, Chen K, Verrill KA. How to Obtain a Nasopharyngeal Swab Specimen. N Engl J Med. 2020;382(22):e76. doi:10.1056/NEJMvcm2010260

53. COMMUNICATION FROM THE COMMISSION. Guidelines on COVID-19 in vitro diagnostic tests and their performance. Brussels, 15.4.2020; C(2020) 2391 final. Available at https://ec.europa.eu/info/sites/info/files/testing kits_communication.pdf

54. Pan Y, Long L, Zhang D, Yuan T, Cui S, Yang P, et al. Potential False-Negative Nucleic Acid Testing Results for Severe Acute Respiratory Syndrome Coronavirus 2 from Thermal Inactivation of Samples with Low Viral Loads. Clin Chem. 2020;66(6):794-801. doi:10.1093/clinchem/hvaa091 55. Woo PC, Lau SK, Wong BH, Chan KH, Chu CM, Tsoi $\mathrm{HW}$, et al. Longitudinal profile of immunoglobulin $\mathrm{G}$ (IgG), $\operatorname{IgM}$, and IgA antibodies against the severe acute respiratory syndrome (SARS) coronavirus nucleocapsid protein in patients with pneumonia due to the SARS coronavirus. Clin Diagn Lab Immunol. 2004;11(4):665-668. doi:10.1128/ CDLI.11.4.665-668.2004

56. Xu W, Li J, HeX, Zhang C, Mei S, LiC, et al. The diagnostic value of joint detection of serum IgM and $\operatorname{IgG}$ antibodies to 2019-nCoV in 2019-nCoV infection. Chinese Journal of Laboratory Medicine, 43(3). https://doi.org/10.3760/cma.j.is sn.1009-9158.2020.03.007 